\title{
Prevalence of depressive symptoms among non insulin treated Greek type 2 diabetic subjects
}

\author{
Alexios Sotiropoulos ${ }^{1}$, Athanasia Papazafiropoulou*1, Ourania Apostolou ${ }^{1}$, \\ Anthi Kokolaki ${ }^{1}$, Aristofanis Gikas ${ }^{2}$ and Stavros Pappas ${ }^{1}$
}

\begin{abstract}
Address: ${ }^{3}$ rd Department of Internal Medicine and Center of Diabetes, General Hospital of Nikaia "Saint Panteleimon" - Piraeus, Greece and ${ }^{2}$ Department of General Practice, Health Centre of Kalivia, Kalivia-Lagonisi, Athens, Greece

Email: Alexios Sotiropoulos - alesot@ath.forthnet.gr; Athanasia Papazafiropoulou* - pathan@ath.forthnet.gr; Ourania Apostolou -s.pappas@nikaia_hosp.gr; Anthi Kokolaki - anthi_xios@yahoo.gr; Aristofanis Gikas - argikas@internet.gr; Stavros Pappas - e.pappa@yahoo.gr

* Corresponding author
\end{abstract}

Published: 28 October 2008

BMC Research Notes 2008, I:10I doi:10.1186/1756-0500-I-101
Received: 28 June 2008

Accepted: 28 October 2008

This article is available from: http://www.biomedcentral.com/I756-0500/I/I0I

(C) 2008 Sotiropoulos et al; licensee BioMed Central Ltd.

This is an Open Access article distributed under the terms of the Creative Commons Attribution License (http://creativecommons.org/licenses/by/2.0), which permits unrestricted use, distribution, and reproduction in any medium, provided the original work is properly cited.

\begin{abstract}
Background: Depression is common among diabetic subjects. We conducted the present study to estimate the prevalence of depression in subjects with type 2 diabetes (T2D) in Greece.
\end{abstract}

Methods: The study sample consisted of 320 T2D subjects without overt macrovascular disease attending the diabetes outpatient clinic of our hospital, from June 2007 to December 2007. Depressive symptoms were measured using the 21 -item Beck Depression Inventory, modified for use in diabetic subjects.

Results: Of the study subjects 107 (33.4\%) reported elevated depressive symptoms. More women than men with diabetes reported symptoms of depression $(48.4 \%$ vs. $12.7 \%, P<0.00 \mathrm{I})$. In the female study group, depressive symptoms were correlated with $\mathrm{HbA}_{\mathrm{Ic}}(P=0.04)$, and duration of diabetes $(P=0.004)$. In the male study group, univariate linear regression analysis showed no significant relationships between depressive symptoms and the testing variables.

Conclusion: The prevalence of depression in Greek T2D subjects is high. Diabetic female subjects showed increased levels of depressive symptoms compared with male subjects. Independent risk factors of depressive symptoms in diabetic female subjects were diabetes duration and glycemic control.

\section{Background}

Depression is common among people with diabetes [1], especially among those with diabetic complications [2]. Depression has been associated with poor adherence to medication [3], poor glycemic control [4], as well as with the development of diabetic complications [5] and increased mortality [6]. Several studies focusing on the prevalence of depression in people with diabetes have been done, showing different depression rates $[7,8]$.

The available data regarding the prevalence of depression among subjects with type 2 diabetes (T2D) in Greece are limited. We, therefore, conducted the present study to evaluate the prevalence of depressive symptoms as well as 
gender differences in subjects with T2D. In addition, the relationship between depressive symptoms and glycemic control was examined.

\section{Methods \\ Population}

The study sample consisted of 320 subjects (age 35-70 years) with T2D attending the diabetes outpatient clinic of our hospital, from June 2007 to December 2007. T2D was diagnosed according to the American Diabetes Association criteria [9]. Subjects with clinically apparent macrovascular disease (coronary, peripheral and carotid artery disease or stroke) and on insulin treatment were excluded since it has been shown that they have high prevalence of depressive symptoms [4,5]. The study protocol was approved by the Scientific and Ethical Committee of the General Hospital of Nikaia.

A detailed medical history was obtained in all study subjects and a full clinical examination was performed. Glycemic control was assessed by measuring of $\mathrm{HbA}_{1 \mathrm{c}}$ (nondiabetic reference range of $4.1-6.0 \%$ ), which is reported to be a reliable indicator of blood glucose level for the last three months prior to testing [10]. Body weight with subjects in light clothing without shoes and height was measured and body mass index (BMI) was calculated.

\section{Assessment of depressive symptoms}

Depressive symptoms were measured using the 21-item Beck Depression Inventory (BDI), modified for use in diabetic subjects, as described in detail elsewhere [11-13]. Each of the 21 items on the BDI measures the presence and severity of a symptom of depression by requiring a self-rating from 0 to 3 . A score is determined by summing the ratings for the individual items [11-13]. The standard cut-offs are as follows: $0-9$ indicates that a person is not depressed, 10-18 indicates mild-moderate depression, 19-29 indicates moderate-severe depression and 30-63 indicates severe depression [11-13]. According to the above scales, we considered as a cutt-off point of elevated depressive symptoms the total score $\geq 19$.

The BDI is designed to examine both somatic and cognitive aspects of depression [11-13]. The BDI has been used, apart from the assessment of the severity of known depression, for screening purposes. Studies have showed that BDI is an effective screening test for depression in diabetic subjects $[12,13]$.

\section{Statistical Analyses}

The following tests were used for the statistical analysis of the data: the student's $t$ test was used to assess differences in continuous variables, while the $\chi^{2}$ test was used for categorical data. Linear regression analysis was used to assess the relationship between depressive symptoms and the parameters of metabolic control. P-values $<0.05$ were considered statistically significant.

\section{Results}

The demographic characteristics of the study population are shown in Table 1. Of the study subjects 107 (33.4\%) reported elevated depressive symptoms. Female diabetic subjects showed more often depressive symptoms than male diabetic subjects (48.4\% vs. $12.7 \%, P<0.001)$ (Figure 1).

In the female study group, univariate linear regression analysis showed significant relationships between depressive symptoms and $\mathrm{HbA}_{1 \mathrm{c}}$ (beta $\left.=0.11, P=0.04\right)$, and duration of diabetes (beta $=0.16, P=0.004)$. No significant associations were found between depressive symptoms and age, BMI, as well as microvascular complications.

In the male study group, univariate linear regression analysis showed no significant relationships between depressive symptoms and the testing variables.

\section{Discussion}

The present study showed that the prevalence of depression in a sample of a Greek T2D people was high. The data regarding the prevalence of depression in $\mathrm{T} 2 \mathrm{D}$ subjects in our country are limited. A previous study reported the frequency of depressive symptoms only in type 1 diabetic patients [14] and another study in elderly subjects with diabetes in primary health care [15]. A recent study in a small sample of elderly diabetic subjects showed no relationship between diabetes and depression [16].

There is evidence that diabetic people are twice as likely to have depression compared with nondiabetic persons $[1,17]$. Approximately $30 \%$ of diabetic subjects have clinically relevant depression $[1,17]$. However, there are studies showing conflicting results. A study in newly identified T2D subjects reported no association between diabetes and depression [18]. Other studies showed that the risk of depression in diabetes increases only when comorbid diseases was present $[19,20]$. In the present study T2D subjects with macrovascular complications were excluded and therefore the observed prevalence of depression among T2D subjects is independent of the presence of comorbid diseases.

The prevalence of depression was significantly higher in females with diabetes compared with males, confirming previous results [21-24]. This pattern is similar to reporting rates in the general population as well as other medical conditions [25-27]. It is known that major depression occurs twice as frequently in women than in men [28] and seems to be influenced by oestrogen levels [29]. A recent 


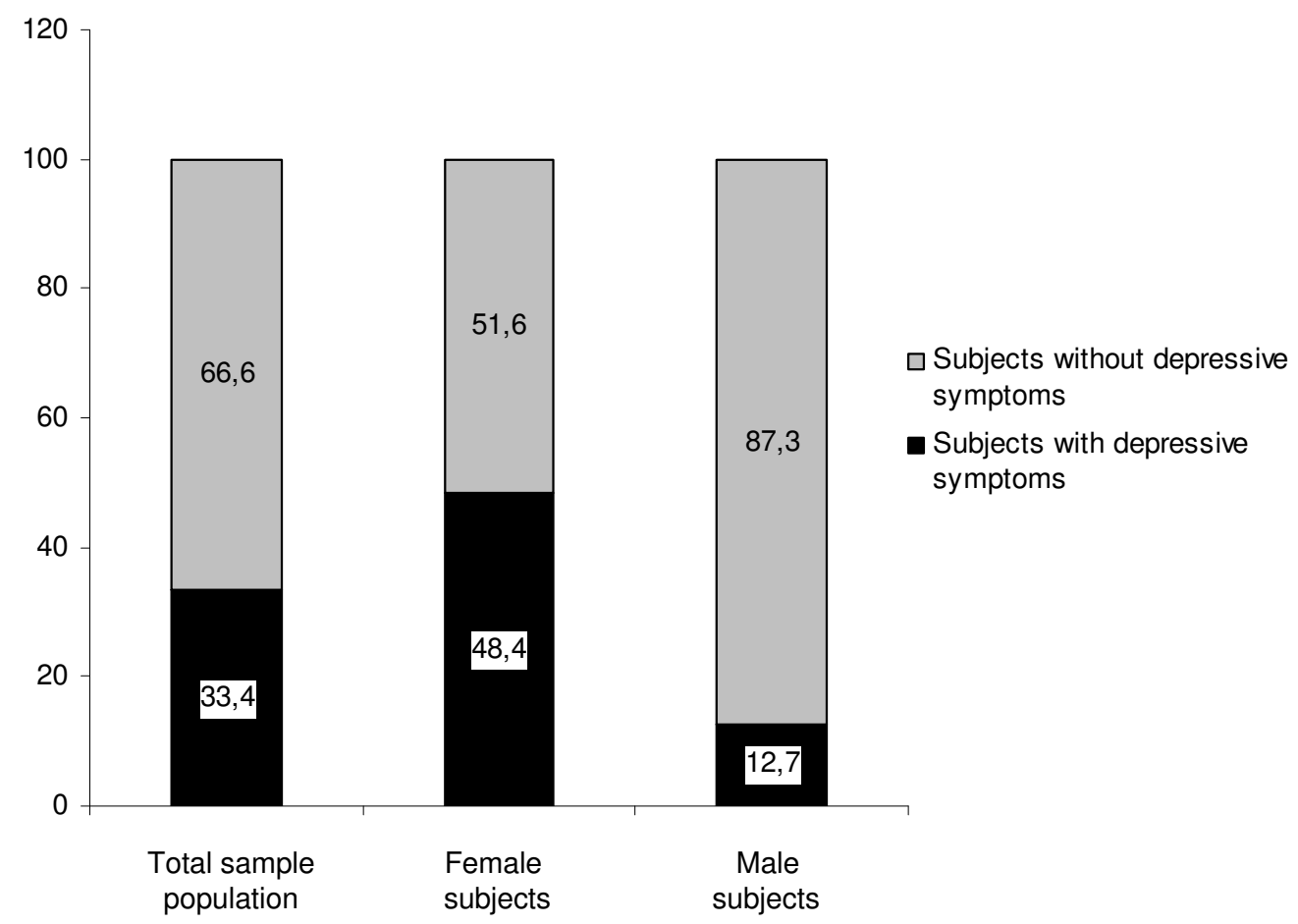

Figure I

The depression prevalence in the total sample population and according to gender (Data are shown as \%).

study suggested that depressive symptoms are associated with a modest increase in the risk of T2D in female subjects [30].

In the female study group depressive symptoms were associated with poor glycemic control and duration of diabetes, confirming previous reports [21-23]. A metaanalysis of 28 studies concluded that depression was associated with hyperglycemia in patients with T2D [31]. On the contrary, a study showed an association between depression and $\mathrm{HbA}_{1 \mathrm{c}}$ levels only in type 1, but not in T2D

Table I: Demographic and clinical characteristics of the study patients.

\begin{tabular}{lccc}
\hline & Males & Females & P-value \\
\hline $\mathrm{n}(\%)$ & $134(4 \mathrm{I} .9)$ & $186(58.1)$ & - \\
Age (years) & $62.8 \pm 6.8$ & $63.6 \pm 7.6$ & $\mathrm{NS}$ \\
$\mathrm{BMI}\left(\mathrm{kg} / \mathrm{m}^{2}\right)$ & $28.9 \pm 4.9$ & $31.2 \pm 5.4$ & $<0.00 \mathrm{I}$ \\
Duration of diabetes (years) & $10.5 \pm 6.1$ & $12.3 \pm 7.2$ & 0.03 \\
$\mathrm{HbA}_{\mathrm{Ic}}(\%)$ & $7.2 \pm 1.3$ & $7.7 \pm 1.7$ & $0.00 \mathrm{I}$ \\
Retinopathy (yes) $\mathrm{n}(\%)$ & $14(10.4)$ & $23(12.4)$ & $\mathrm{NS}$ \\
Neuropathy (yes) $\mathrm{n}(\%)$ & $13(9.7)$ & $19(10.2)$ & $\mathrm{NS}$ \\
Nephropathy (yes) $\mathrm{n}(\%)$ & $2(1.5)$ & $4(2.2)$ & $\mathrm{NS}$ \\
Depression (yes) $\mathrm{n}(\%)$ & $17(12.7)$ & $90(48.4)$ & $<0.00 \mathrm{I}$ \\
\hline
\end{tabular}

Data are shown as mean $\pm \mathrm{SD}$ or as $\mathrm{n}(\%)$. patients [24]. Another studies showed that depression does not influence metabolic control in diabetic people [32] and that depression appears to be stronger in men than in women [33].

In this study, we did not find any relationship between depression and BMI, in contrast to two studies showing higher BMI in depressed than non depressive diabetic subjects [1,34]. In addition, no relationship was found between depressive symptoms and microvascular complications, although previous studies have reported the opposite $[35,36]$.

Our study has some limitations. Data were collected from an outpatient diabetic clinic. A possible selection bias could not be excluded since the more concerned diabetic patients might seek a specialized diabetes care. Our assessment of depression was based on self-report of symptoms using a validated instrument, not on the more accurate clinical diagnostic interview. Furthermore, data on demographic characteristics of the study subjects were not available. Studies have showed that depressive symptoms are higher in diabetic people with lower income as well lower education level [37]. Finally, diabetic subjects on insulin therapy and with macrovascular disease were excluded 
and therefore our results can not be extrapolated to the diabetic population.

In conclusion, the present study showed that the prevalence of depression in Greek T2D subjects without overt macrovascular complications is comparable to findings from the recent literature. Diabetic female subjects showed increased levels of depressive symptoms compared with male subjects. Independent risk factors of depressive symptoms were diabetes duration and glycemic control.

\section{Competing interests}

The authors declare that they have no competing interests.

\section{Authors' contributions}

All authors participated in the collection, analysis, interpretation of data and writing of the paper.

\section{References}

I. Gavard JA, Lustman PJ, Clouse RE: Prevalence of depression in adults with diabetes. An epidemiological evaluation. Diabetes Care 1993, 16:1167-1178.

2. Katon W, von Korff M, Ciechanowski P, Russo J, Lin E, Simon G, Ludman E, Walker E, Bush T, Young B: Behavioral and clinical factors associated with depression among individuals with diabetes. Diabetes Care 2004, 27:9|4-920.

3. Lin EH, Katon W, Von Korff M, Rutter C, Simon GE, Oliver M, Ciechanowski P, Ludman EJ, Bush T, Young B: Relationship of depression and diabetes self-care, medication adherence, and preventive care. Diabetes Care 2004, 27:2I54-2I60.

4. Lustman PJ, Anderson RJ, Freedland KE, de Groot M, Carney RM, Clouse RE: Depression and poor glycemic control: a metaanalytic review of the literature. Diabetes Care 2000, 23:934-942.

5. Black SA, Markides KS, Ray LA: Depression predicts increased incidence of adverse health outcomes in older Mexican Americans with type 2 diabetes. Diabetes Care 2003, 26:2822-2828

6. Katon WJ, Rutter C, Simon G, Lin EH, Ludman E, Ciechanowski P, Kinder L, Young B, Von Korff M: The association of comorbid depression with mortality in patients with type 2 diabetes. Diabetes Care 2005, 28:2668-2672.

7. Carney C: Diabetes mellitus and major depressive disorder: an overview of prevalence, complications, and treatment. Depress Anxiety 1998, 7:149-157.

8. Lustman PJ, Griffith LS, Gavard JA, Clouse RE: Depression in adults with diabetes. Diabetes Care 1992, I5:1631-1639.

9. The Expert Committee on the Diagnosis and Classification of Diabetes Mellitus: Report of the Expert Committee on the Diagnosis and Classification of Diabetes Mellitus. Diabetes Care 200I, 24:S5-S20.

10. Nethan DM, Singer DE, Hursthal K: The clinical information value of the glycosylated hemoglobin assay. N EnglJ Med I 984, 3 1 0:341-346.

II. Beck AT, Ward CH, Mendelson M, Mock JD, Erbaugh J: An inventory for measuring depression. Arch Gen Psychiatry I 96I, 4:53-63.

12. Lustman PJ, Freedland KE, Carney RM, Hong BA, Clouse RE: Similarity of depression in diabetic and psychiatric patients. Psychosom Med 1992, 54:602-6II.

13. Lustman PJ, Clouse RE, Griffith LS, Carney RM, Freedland KE: Screening for depression in diabetes using the Beck Depression Inventory. Psychosom Med 1997, 59:24-3I.

14. Liamou EA, Mylonakis EE, Karamitsos DT: Frequency of depression in IDDM patients in Greece. Diabetes Care 1994, I 7:1075.

15. Argyriadou S, Melissopoulou H, Krania E, Karagiannidou A, Vlachonicolis I, Lionis C: Dementia and depression: two frequent disorders of the aged in primary health care in Greece. Fam Pract 200I, I8:87-9|.
16. Dimopoulos N, Piperi C, Salonicioti A, Psarra V, Gazi F, Papadimitriou A, Lea RW, Kalofoutis A: Correlation of folate, vitamin B I 2 and homocysteine plasma levels with depression in an elderly Greek population. Clin Biochem 2007, 40:604-608.

17. Egede LE: Effect of depression on self-management behaviours and health outcomes in adults with type 2 diabetes. Curr Diabetes Rev 2005, I:235-243.

18. Brown LC, Majumdar SR, Newman SC, Johnson JA: Type 2 diabetes does not increase risk of depression. CMAJ 2006, I 75:42-46.

19. Bisschop MI, Kriegsman DM, Deeg DJ, Beekman AT, van Tilburg W: The longitudinal relation between chronic diseases and depression in older persons in the community: the Longitudinal Aging Study Amsterdam. J Clin Epidemiol 2004, 57: I87- I 94.

20. Rajala U, Keinanen-Kiukaanniemi S, Kivela SL: Non-insulin-dependent diabetes mellitus and depression in a middle aged Finnish population. Soc Psychiatry Psychiatr Epidemiol 1997, 32:363-367.

21. Ali S, Stone MA, Peters JL, Davies MJ, Khunti K: The prevalence of co-morbid depression in adults with Type 2 diabetes: a systematic review and meta-analysis. Diabet Med 2006, 23: I 165-II73.

22. Goldney RD, Phillips PJ, Fisher LJ, Wilson DH: Diabetes, depression and quality of life. A population based study. Diabetes Care 2004, 27:1066-1070.

23. Pibermik-Okanovic M, Peros K, Szabo S, Begic D, Metelko Z: Depression in Croatian Type 2 diabetic patients: prevalence and risk factors. A Croatian survey from the European Depression in Diabetes (EDID) Research Consortium. Diabet Med 2005, 22:942-945.

24. Anderson RJ, Freedland KE, Clouse RE, Lustman PJ: The prevalence of comorbid depression in adults with diabetes: a meta-analysis. Diabetes Care 200I, 24:1069-1078.

25. Piccinelli $M$, Wilkinson G: Gender differences in depression. $\mathrm{Br} J$ Psychiatry 2000, I 77:486-492.

26. Carney RM, Freedland KE, Sheline YI, Weiss ES: Depression and coronary heart disease: a review for cardiologists. Clin Cardiol 1997, 20:196-200.

27. Bottomly A: Depression in cancer patients: a literature review. Eur J Cancer Care 1998, 7:181.

28. Culbertson FM: Depression and gender: an international review. Am Psychol 1997, 52:25-31.

29. Archer JS: Relationship between estrogen, serotonin, and depression. Menopause 1999, 6:71-78.

30. Arroyo C, Hu FB, Ryan LM, Kawachi I, Colditz GA, Speizer FE, Manson J: Depressive symptoms and risk of type 2 diabetes in women. Diabetes Care 2004, 27:129-133.

31. Lustmann PJ, Anderson RJ, Freedland KE, De Groot M, Carney RM, Clouse RE: Depression and poor glycemic control: A metaanalytic review of the literature. Diabetes Care 2000, 23:934-942.

32. Ciechanowski PS, Katon WJ, Russo JE, Hirsch IB: The relationship of depressive symptoms to symptom reporting, self-care and glucose control in diabetes. General Hospital Psychiatry 2003, 25:246-252

33. Paschalides C, Wearden AJ, Dunkerley R, Bundy C, Davies R, Dickens $C M$ : The associations of anxiety, depression and personal illness representations with glycaemic control and healthrelated quality of life in patients with type 2 diabetes mellitus. Journal of Psychosomatic Research 2004, 57:557-564.

34. Sacco WP, Wells KJ, Friedman A, Matthew R, Perez S, Vaughan CA: Adherence, body mass index, and depression in adults with type 2 diabetes: the mediational role of diabetes symptoms and self-efficacy. Health Psychol 2007, 26:693-700.

35. Bruce DG, Davis WA, Starkstein SE, Davis TM: A prospective study of depression and mortality in patients with type 2 diabetes: the Fremantle Diabetes Study. Diabetologia 2005, 48:2532-2539.

36. Golden SH, Lee HB, Schreiner PJ, Roux AD, Fitzpatrick AL, Szklo M, Lyketsos C: Depression and type 2 diabetes mellitus: the multiethnic study of atherosclerosis. Psychosom Med 2007, 69:529-536.

37. Thomas J, Jones G, Scarinci I, Brantley P: A descriptive and comparative study of the prevalence of depressive and anxiety disorders in low-income adults with type $\mathbf{2}$ diabetes and other chronic illnesses. Diabetes Care 2003, 26:23 I I-23 I 7. 